\title{
Exendin-4 improves cardiovascular function and survival in flow-induced pulmonary hypertension
}

\author{
Jun-Neng Roan, MD, PhD, ${ }^{\mathrm{a}}$ Chih-Hsin Hsu, MD, PhD, ${ }^{\mathrm{b}}$ Shih-Yuan Fang, MD, ${ }^{\mathrm{c}}$ Hung-Wen Tsai, MD, PhD, ${ }^{\mathrm{d}}$ \\ Chwan-Yau Luo, MD, MSc, ${ }^{a}$ Chien-Chi Huang, MSc, ${ }^{c}$ and Chen-Fuh Lam, MD, $\mathrm{PhD}^{\mathrm{c}, \mathrm{e}}$
}

\section{ABSTRACT}

Objectives: Systemic left-to-right shunting causes pulmonary arteriopathy, leading to progressive cardiopulmonary failure and a poor prognosis. In this study, we examined the extraglycemic effect of a synthetic glucagon-like peptide, exendin-4, on pulmonary arteriopathy regression and cardiopulmonary function in nondiabetic rats.

Methods: Pulmonary hypertension (PH) was induced by monocrotaline $(60 \mathrm{mg} / \mathrm{kg}$, subcutaneous) injection followed by the creation of an aortocaval fistula. After 4 weeks, exendin-4 ( $1 \mu \mathrm{g} / \mathrm{kg} / \mathrm{day})$ was administered intraperitoneally for 3 consecutive weeks, followed by an assessment of cardiopulmonary function, pulmonary artery vasoreactivity, tissue and blood biochemistry, and lung histology.

Results: Exendin-4 significantly reduced right ventricle mass and pulmonary artery pressure, which improved right ventricle function and the survival rate in rats with $\mathrm{PH}$. Tissue and blood interleukin- $1 \beta$ levels decreased, whereas pulmonary artery cyclic adenosine monophosphate levels were restored by exendin-4. Smooth muscle-myosin heavy chain-II and $\alpha$-smooth muscle actin protein levels increased in the pulmonary arteries of exendin-4-treated rats. Histology showed that exendin- 4 decreased the main and intra-acinar pulmonary artery medial thickness.

Conclusions: Exendin-4 treatment improved pulmonary artery function in flow-induced PH via its direct vasoactive properties, anti-inflammatory effects, and vascular smooth muscle cell phenotypic modulation. Mitigation of pulmonary arteriopathy further potentiated right ventricle performance and reduced overall mortality. These responses were associated with suppressed expression and activity of interleukin- $1 \beta$ and its downstream signaling molecules. Glucagon-like peptide analogs may possess pleiotropic therapeutic potential in flow-induced PH. (J Thorac Cardiovasc Surg 2018;155:1661-9)

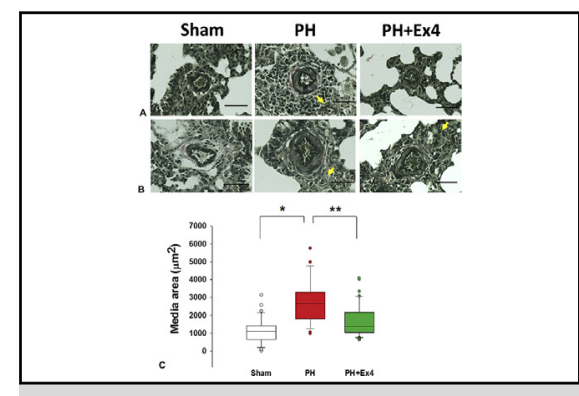

Exendin-4 attenuated pulmonary vessel hyperplasia in flow-induced pulmonary hypertension.

\section{Central Message}

Our study highlights the beneficial extraglycemic effect of exendin- 4 as a potential therapeutic agent for regression of pulmonary arteriopathy secondary to flow-induced pulmonary hypertension.

\section{Perspective}

This study demonstrates that exendin-4, a glucagon-like peptide-1 analog, attenuates the progress of pulmonary arteriopathy and restores right ventricular performance, thereby reducing the overall survival of animals with flow-induced pulmonary hypertension. The pleiotropic effects of exendin-4 in pulmonary vascular remodeling may provide therapeutic potential in pulmonary hypertension secondary to increased pulmonary flow.

See Editorial Commentary page 1670.

\footnotetext{
From the ${ }^{\mathrm{a}}$ Division of Cardiovascular Surgery, Department of Surgery, ${ }^{\mathrm{c}}$ Departments of Anesthesiology, and ${ }^{\mathrm{d}}$ Pathology, National Cheng Kung University Hospital, and ${ }^{\mathrm{b}}$ Division of Cardiology, Department of Internal Medicine, College of Medicine, National Cheng Kung University, Tainan, Taiwan; and ${ }^{\mathrm{e}}$ E-Da Hospital/I-Shou University, Kaohsiung City, Taiwan.

Supported by grants from the National Cheng Kung University Hospital (No. NCKUH-10407002 to J.N.R.) and the National Science Council of Taiwan (No. MOST 105-2314-B-006 -068 to J.N.R. and MOST 105-2314-B-303-007MY2 to C.F.L.).

Received for publication Jan 10, 2017; revisions received Sept 16, 2017; accepted for publication Oct 6, 2017; available ahead of print Dec 14, 2017.

Address for reprints: Chen-Fuh Lam, MD, PhD, Department of Anesthesiology, E-Da Hospital/I-Shou University, 1 Yida Rd, Yanchao District, Kaohsiung City 824, Taiwan (E-mail: ed110208@edah.org.tw).

$0022-5223 / \$ 36.00$

Copyright (c) 2017 by The American Association for Thoracic Surgery

https://doi.org/10.1016/j.jtcvs.2017.10.085
}

Pulmonary arterial hypertension (PAH) is a devastating disease that affects 15 to 60 per million people. ${ }^{1} \mathrm{PAH}$ is characterized by progressive remodeling of the pulmonary arterial system and the development of pulmonary arteriopathy secondary to the presence of systemic left-toright shunts, use of pharmaceuticals, or genetic defects

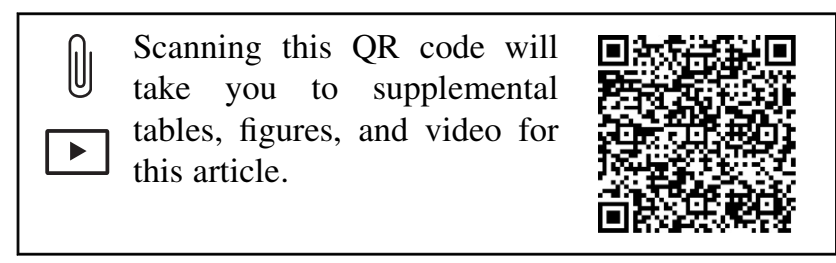




$\begin{array}{ll}\text { Abbreviations and Acronyms } \\ \alpha \text {-SMA } & =\alpha \text {-smooth muscle actin } \\ \text { cAMP } & =\text { cyclic adenosine monophosphate } \\ \text { c-GMP } & =\text { cyclic guanosine monophosphate } \\ \text { eNOS } & =\text { endothelial nitric oxide synthase } \\ \text { Ex4 } & =\text { exendin-4 } \\ \text { Glp-1 } & =\text { glucagon-like peptide-1 } \\ \text { IL } & =\text { interleukin } \\ \text { LV } & =\text { left ventricle } \\ \text { p } & =\text { phosphorylated } \\ \text { PA } & =\text { pulmonary artery } \\ \text { PAH } & =\text { pulmonary arterial hypertension } \\ \text { PH } & =\text { pulmonary hypertension } \\ \text { RV } & =\text { right ventricle } \\ \text { SM-MHC II } & =\text { smooth muscle myosin heavy chain } \\ & \text { class II } \\ \text { VSMC } & =\text { vascular smooth muscle cell }\end{array}$

such as bone morphogenetic protein receptor type II mutation. ${ }^{2}$ Approximately $30 \%$ of patients with congenital heart disease develop PAH due to excessive pulmonary blood flow $^{3}$; their quality of life inevitably deteriorates, and long-term survival is shortened. ${ }^{3,4}$ The survival of patients with congenital heart disease-associated PAH worsens with the development of Eisenmenger syndrome. ${ }^{5}$ Although PAH management has improved considerably, therapeutic approaches for advanced flow-induced pulmonary hypertension $(\mathrm{PH})$ are currently limited. ${ }^{6}$

Glucagon-like peptide 1 (Glp-1), a glucose-dependent insulinotropic peptide, belongs to the incretin family ${ }^{7}$ and exerts its pharmacologic actions by adenylate cyclase-mediated activation of heptahelical G proteincoupled receptor. ${ }^{8}$ In addition to its glucoregulatory effects, Glp-1 and its agonists, including exendin-4 (Ex4), have shown cardiovascular protection in experimental studies. ${ }^{9}$ Ex4 is a Glp-1 analog that is present in the saliva of the Gila monster (Heloderma suspectum); it has been found to reduce neointimal hyperplasia following arterial injury. ${ }^{10}$ It also suppresses inflammatory cytokine generation by activating adenylate cyclase and the production of cyclic adenosine monophosphate (cAMP) in monocytes and macrophages. ${ }^{11}$ Furthermore, Ex4 attenuates hyperoxide-induced senescence in cultured vascular smooth muscle cells (VSMCs). ${ }^{12}$ Commonly reported adverse effects of Ex4 for treatment of diabetes include nausea, vomiting, and body weight loss. ${ }^{7,9}$ Together, we tested our hypothesis that the vascular protective and pleiotropic effects of Ex4 in modulating VSMC phenotypes and inflammatory reactions may have therapeutic potential in regressing flow-induced $\mathrm{PH}$ (Figure E1).

\section{METHODS \\ Induction of $\mathbf{P H}$ in rats}

All procedures were conducted in accordance with the Animal Care and Use Committee of National Cheng Kung University guidelines (approval No. 104051). Age-matched male Sprague-Dawley rats (weight, 200-250 g) were maintained on a 12-hour light-dark cycle. Single doses $(60 \mathrm{mg} / \mathrm{kg}$ ) of monocrotaline (Sigma-Aldrich Chemical Corp, St Louis, Missouri) were injected subcutaneously, followed by the creation of systemic left-to-right shunts that induce clinically comparable flow-induced $\mathrm{PH}^{13}$ Aortocaval shunts were created 7 days after monocrotaline injection, and the animals were expected to develop symptoms of right heart failure 2 to 3 weeks later. ${ }^{13}$ Surgical procedures used to create the aortocaval shunt have been described previously (Video 1). ${ }^{14,15}$

\section{Treatment Protocol}

From week 4 after monocrotaline injection, flow-induced $\mathrm{PH}$ rats were randomly allocated to receive regular intraperitoneal injections of placebo $\left(1 \mathrm{~mL}\right.$ normal saline daily) or Ex4 $(1 \mu \mathrm{g} / \mathrm{kg} / \mathrm{day})^{16}$ as the PH and PH $+\mathrm{Ex} 4$ groups, respectively, for 3 weeks. The animals received standard chow and water ad libitum throughout the study. A total of 116 animals were included in the study analysis, and the number of animals used in each experiment is indicated in Video 1 and each figure legend. The personnel who performed hemodynamic assessments were blinded to the treatment groups.

\section{Hemodynamic Measurements and Vasomotor Function Assessment}

Echocardiography. Transthoracic echocardiography was performed on anesthetized rats immediately before euthanasia, as previously described. ${ }^{15}$

Invasive hemodynamic assessment. Rats were anesthetized using isoflurane $(2 \%-3 \% \mathrm{v} / \mathrm{v}$ in oxygen) inhalation as previously described. ${ }^{17}$ Rat hearts were exposed and the RV and LV were directly punctured using a $23 \mathrm{G}$ needle connected to a pressure transducer (Kent Scientific Corporation, Torrington, Connecticut) to measure the blood pressure. ${ }^{18}$ Right ventricle (RV) systolic pressure was used as a surrogate indicator of pulmonary artery (PA) pressure. ${ }^{19}$ The rats were put to death after the invasive hemodynamic measurements. The hearts and lungs were removed en bloc for analysis including lung wet-to-dry ratio. ${ }^{20}$

RV morphologic analysis. The rat hearts were dissected to isolate the free wall of the RV from the left ventricle (LV) and septum. The RV/ $\mathrm{LV}+$ septum mass ratio was the index (Fulton index) of RV hypertrophy. ${ }^{19}$

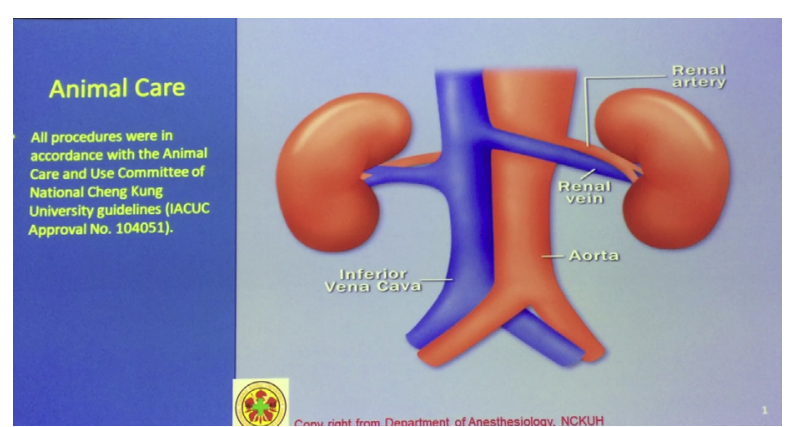

VIDEO 1. An animated presentation of the "2-hit" model of flow-induced pulmonary hypertension shows the surgical techniques. The treatment protocol and a summary of the limitations of this animal model are also included as supplementary material. Video available at: http://www. jtcvsonline.org/article/S0022-5223(17)32432-7/fulltext. 
Vasomotor function assessment. The main PA rings ( $\sim 3 \mathrm{~mm}$ long) were mounted in organ chambers containing $25 \mathrm{~mL}$ Krebs solution, and the vasomotor function of PA was assessed by isometric tension recordings. ${ }^{15}$

\section{Quantitative Analysis of Serum Inflammatory Markers and Blood Chemistry}

Blood samples were collected before the rats were put to death. Serum interleukin (IL)-1 $\alpha$, IL-1 $\beta$, IL-2, IL-6, monocyte chemoattractant protein-1, and tumor necrosis factor- $\alpha$ concentrations were quantified using sandwich cytokine-specific enzyme-linked immunosorbent assay detection kits (eBioscience, Frankfurt, Germany). Blood glucose, triglyceride, cholesterol, and creatinine levels were analyzed using colorimetric assays (ADVIA 1800 Chemistry System; Siemens, Munich, Germany). ${ }^{21}$

Immunoblotting. The proteins extracted from PA tissues $(50 \mu \mathrm{g})$ were prepared for incubation with appropriate primary antibodies, as previously described. ${ }^{15,22}$

Histology of PAs and arterioles. The PA and lung tissue samples were fixed in $4 \%$ paraformaldehyde, paraffin wax-embedded, and cut into $5-\mu \mathrm{m}$ sections, which were stained with hematoxylin and eosin and Verhoeff stains. The slides were analyzed under light microscopy by observers who were blinded to the treatment groups. The intra-acinar pulmonary arterioles were defined as vessels with diameters $<150 \mu \mathrm{m} .{ }^{23}$ Twenty arterioles or slices of arteries were measured per animal under $400 \times$ magnification to determine the medial thickness.

Measurement of tissue cAMP and cyclic guanosine monophosphate. PA tissue segments were incubated in Earle's salts solution as previously described. ${ }^{22}$ Tissue cyclic guanosine monophosphate (cGMP) and cAMP concentrations were determined by enzymelinked immunosorbent assay (R\&D System, Minneapolis, Minnesota).

Immunohistochemistry. Immunohistochemistry was performed for the above-described tissue sections using a Bond-Max Automated IHC stainer (Leica Biosystems Newcastle Ltd, Melbourne, Australia). The sections were incubated with rabbit anti-IL-1 $\beta$ (1:200 dilution) at $25^{\circ} \mathrm{C}$ for 30 minutes and counterstained with hematoxylin. Quantification was performed using ImageJ software (National Institutes of Health, Rockville, Md).

\section{Statistical Analysis}

The results are presented as the mean \pm standard deviation or median with 25 th to 75 th percentiles, as appropriate. Differences in survival rates were analyzed using the $\chi^{2}$ and the log-rank tests for Kaplan-Meier curves. Intergroup differences were analyzed using the Student $t$ test or 1-way analysis of variance followed by appropriate post hoc tests for multiple comparisons. The concentration curves in the vasomotor function analysis were analyzed using 2-way repeated measures analysis of variance with post hoc Holm-Sidak tests. The post hoc Tukey or Dunn test was used as appropriate for nonparametric analysis.

\section{RESULTS}

\section{Ex4 Suppressed Serum Inflammatory Cytokines and Improved Survival}

No significant changes were observed in body weight or in blood glucose, triglyceride, total cholesterol, and creatinine levels in the Ex4-treated animals (Table E1). Ex4 significantly reduced serum IL- $1 \alpha$ and IL- $1 \beta$ concentrations in PH rats (Table 1). During the 3-week treatment, Ex4 significantly improved the survival rate of rats with flow-induced $\mathrm{PH}(77.8 \%$ vs $25.0 \%$ for $\mathrm{PH}+$ Ex4 vs $\mathrm{PH}$ on treatment day $21 ; P=.006)$ (Figure 1, A). The RV/LV + septum ratio was restored,
TABLE 1. Serum inflammatory markers in rats with flow-induced pulmonary hypertension (PH)

\begin{tabular}{lccc}
\hline Inflammatory marker & PH & PH + Ex4 & $P$ value \\
\hline IL-1 $\alpha(\mathrm{ng} / \mathrm{mL})$ & $44.08 \pm 9.54$ & $11.58 \pm 3.04$ & .005 \\
IL-1 $\beta(\mathrm{pg} / \mathrm{mL})$ & $203.60 \pm 55.92$ & $34.13 \pm 13.55$ & .019 \\
IL-2 $(\mathrm{ng} / \mathrm{mL})$ & $28.35 \pm 4.48$ & $26.85 \pm 6.43$ & .838 \\
IL-6 $(\mathrm{pg} / \mathrm{mL})$ & $21.32 \pm 1.75$ & $29.03 \pm 10.45$ & .981 \\
MCP-1 $(\mathrm{pg} / \mathrm{mL})$ & $285.71 \pm 10.89$ & $330.35 \pm 40.42$ & .421 \\
TNF- $\alpha(\mathrm{pg} / \mathrm{mL})$ & $2.37 \pm 0.19$ & $1.82 \pm 0.14$ & .067 \\
\hline
\end{tabular}

Values are presented as mean \pm standard error of the mean $(n=6 /$ group). Data from the sham group are not shown due to low serum titers. $P H$, Pulmonary hypertension; Ex4, exendin-4; IL, interleukin; $M C P-1$, monocyte chemoattractant protein-1; $T N F-\alpha$, tumor necrosis factor- $\alpha$.

and lung wet-to-dry ratio was reduced (Figure 1, B and $C)$. The major cause of death was heart failure.

\section{Ex4 Improved RV Function}

Ex4 significantly reduced the PA diameter and enhanced the peak flow velocity across the RV outflow track (Table 2 and Figure E2). The RV diameter and tricuspid peak flow were restored in $\mathrm{PH}+\mathrm{Ex} 4$ rats (Table 2). Ex4 treatment also significantly reduced RV systolic pressure and adjusted RV systolic pressure (RV systolic pressure peak $_{\text {- }}$ - - LV systolic pressure $_{\text {peak }}$ ratio) (Table E2). ${ }^{24}$ The LV ejection fraction was unaffected by Ex4 treatment $(P=.417)$ (Table 2). Additionally, the LV systolic and diastolic pressures were augmented in the $\mathrm{PH}+\mathrm{Ex} 4$ group (Table E2).

\section{Ex4 Potentiated the Vasomotor Function of PAs}

Isometric contractions were significantly increased in response to potassium chloride $(40 \mathrm{mM})$ and phenylephrine $\left(10^{-9}-10^{-5} \mathrm{M}\right)$ in the PA of flow-induced PH rats (Figure 2, $A$ and $B$ ), whereas Ex4 treatment significantly attenuated the potassium chloride- and phenylephrine-induced contractions (Figure 2, $A$ and $B$ ). Endothelial-dependent relaxation in response to acetylcholine was significantly impaired in the PA of PH rats, and the relaxation curve was potentiated in Ex4-treated rats (Figure 2, C). Endothelial-independent relaxations were shifted to the right in rats with flow-induced $\mathrm{PH}$ but were not potentiated by Ex4 (Figure 2, D).

\section{Ex4 Enhanced cAMP and cGMP Biosynthesis in the PAs}

The high pulmonary blood flow marginally increased endothelial nitric oxide synthase (eNOS) protein levels in the PAs $(P=.059)$ (Figure $3, A$ and $B)$, whereas phosphorylated (p)-eNOS expression significantly increased (Figure 3,C). Ex4 did not affect the protein levels of eNOS, p-eNOS, or heat shock protein in PAs exposed to chronic high blood flow (Figure 3, A-D); however, 


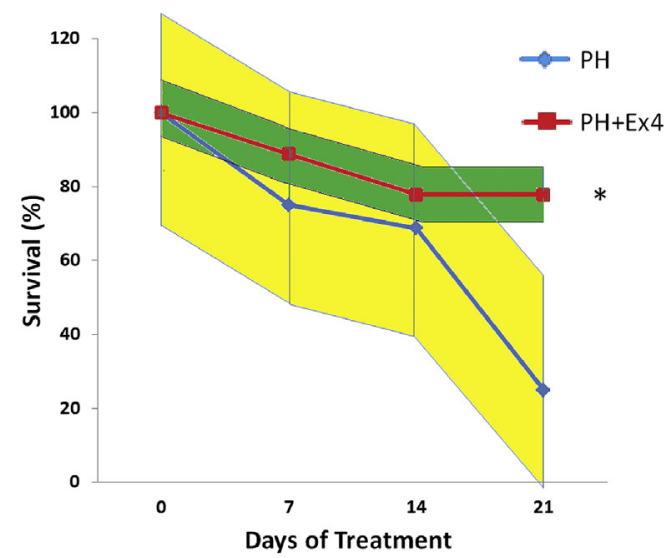

\section{B}
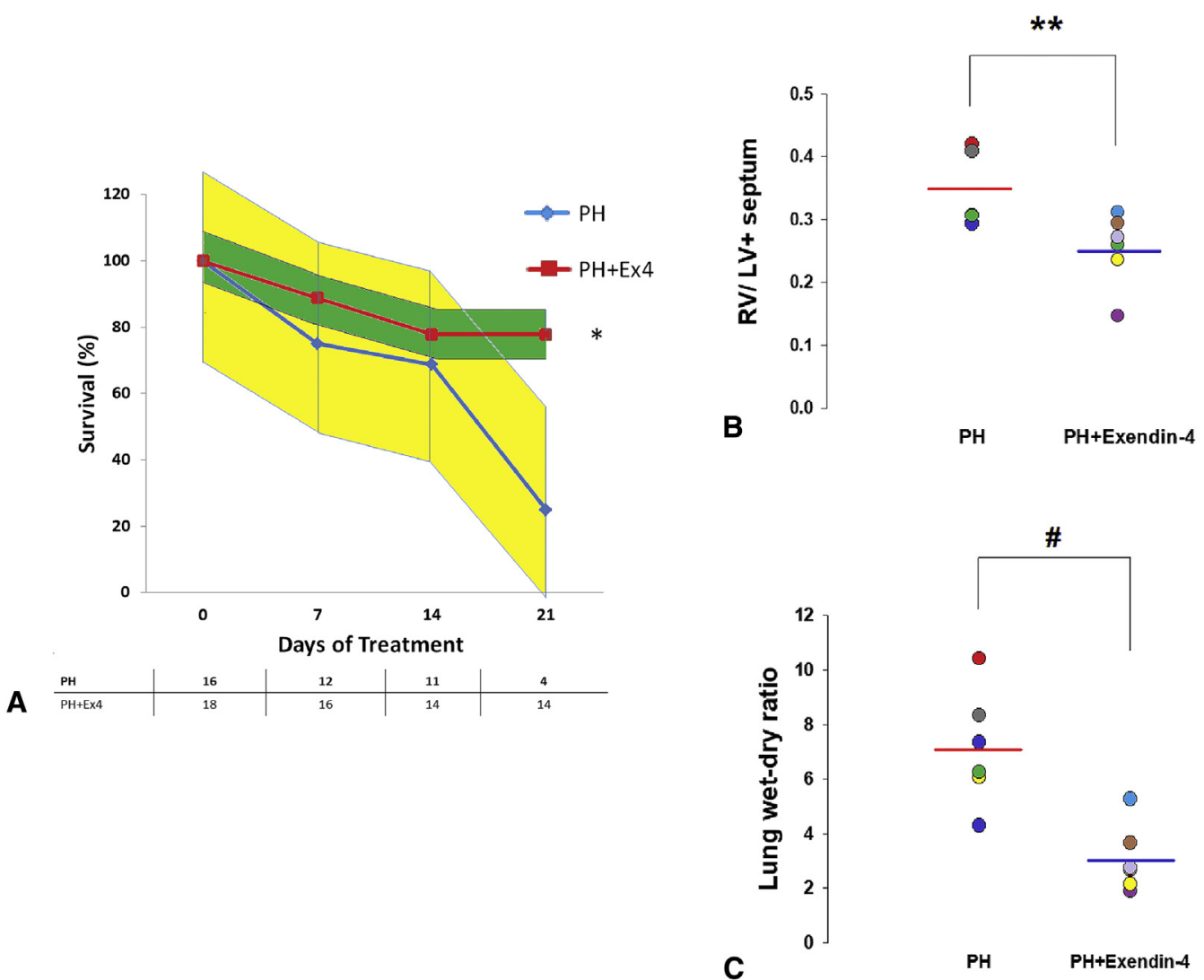

FIGURE 1. Cardiopulmonary effects and survival of rats with flow-induced pulmonary hypertension $(P H)$. A, Survival outcomes with $95 \%$ confidence intervals of PH rats treated with and without Exendin-4 (Ex4) for 3 weeks; $\mathrm{n}=16$ and 18 for PH and PH + Ex4 groups, respectively. B, Right ventricle $(R V)$ weight adjusted to weight of the left ventricle $(L V)$ with septum (Fulton index); $\mathrm{n}=6$ for both groups. C. Lung wet:dry ratio on the day of euthanasia; $\mathrm{n}=6 /$ both groups. The dashed line in $\mathrm{B}$ and $\mathrm{C}$ indicates sham group. ${ }^{*} P<.001$ using the log-rank test. $* * P=.031 .{ }^{*} P=.037$.

Ex4 significantly increased both cGMP and cAMP concentrations in the $\mathrm{PA}$ of $\mathrm{PH}$ rats $(P<.001$ and $P=.007$, respectively) (Figure $3, E$ and $F$ ).

\section{Ex4 Suppressed IL-1 $\beta$ and Associated Proteins in the PAs}

Caspase-1 (an interleukin-converting enzyme), IL-1 $\beta$, and its downstream signaling proteins (p-P38 mitogenactivated protein kinase, total-extracellular signal-regulated kinase $1 / 2$, and $p$ - extracellular signal-regulated kinase $1 / 2$ ) were significantly upregulated in the PA of rats with flow-induced PH (Figure E3). Furthermore, Ex4 suppressed the abundance of caspase- 1 and IL- $1 \beta$-associated proteins in the PA (Figure E3).

\section{Ex4 Modulated VSMC Phenotypes in PAs}

The abundance of smooth muscle myosin heavy chain class II (SM-MHC II) and $\alpha$-smooth muscle actin $(\alpha$-SMA) decreased in the flow-induced PH animals (Figure 4), whereas Ex4 restored the abundance of these

TABLE 2. Echocardiographic measurements

\begin{tabular}{lrrrr}
\hline \multicolumn{1}{c}{ Variable } & \multicolumn{1}{c}{ Sham } & \multicolumn{1}{c}{ PH } & PH + Ex4 & P value \\
\hline Main pulmonary artery diameter $(\mathrm{mm})$ & $2.87 \pm 0.20$ & $3.76 \pm 0.38^{*}$ & $2.71 \pm 0.15$ & .009 \\
Pulmonary artery peak flow velocity $(\mathrm{cm} / \mathrm{s})$ & $74.23 \pm 7.00$ & $59.42 \pm 6.09 \dagger$ & $82.16 \pm 6.45$ & .046 \\
Right ventricle diameter $(\mathrm{mm})$ & $4.08 \pm 0.09$ & $5.49 \pm 0.34 \ddagger$ & $4.19 \pm 0.40$ \\
Tricuspid peak flow velocity $(\mathrm{cm} / \mathrm{s})$ & $68.85 \pm 4.45$ & $102.78 \pm 9.52 \S$ & $82.44 \pm 5.54$ \\
Left ventricle ejection fraction $(\%)$ & $68.75 \pm 3.47$ & $65.91 \pm 3.60$ & $72.31 \pm 3.17$ \\
\hline
\end{tabular}

Values are presented as mean \pm standard error of the mean ( $\mathrm{n}=6$ /group). $P H$, Pulmonary hypertension; $E x 4=$ exendin- $4 . * P<.05$ versus other groups using the post hoc Tukey method. $\dagger P<.05$ versus PH + Ex4 with the post hoc Dunn’s method. $¥ P<.05$ versus other groups using the post hoc Tukey method. $\S P<.05$ versus sham using the post hoc Tukey method. 

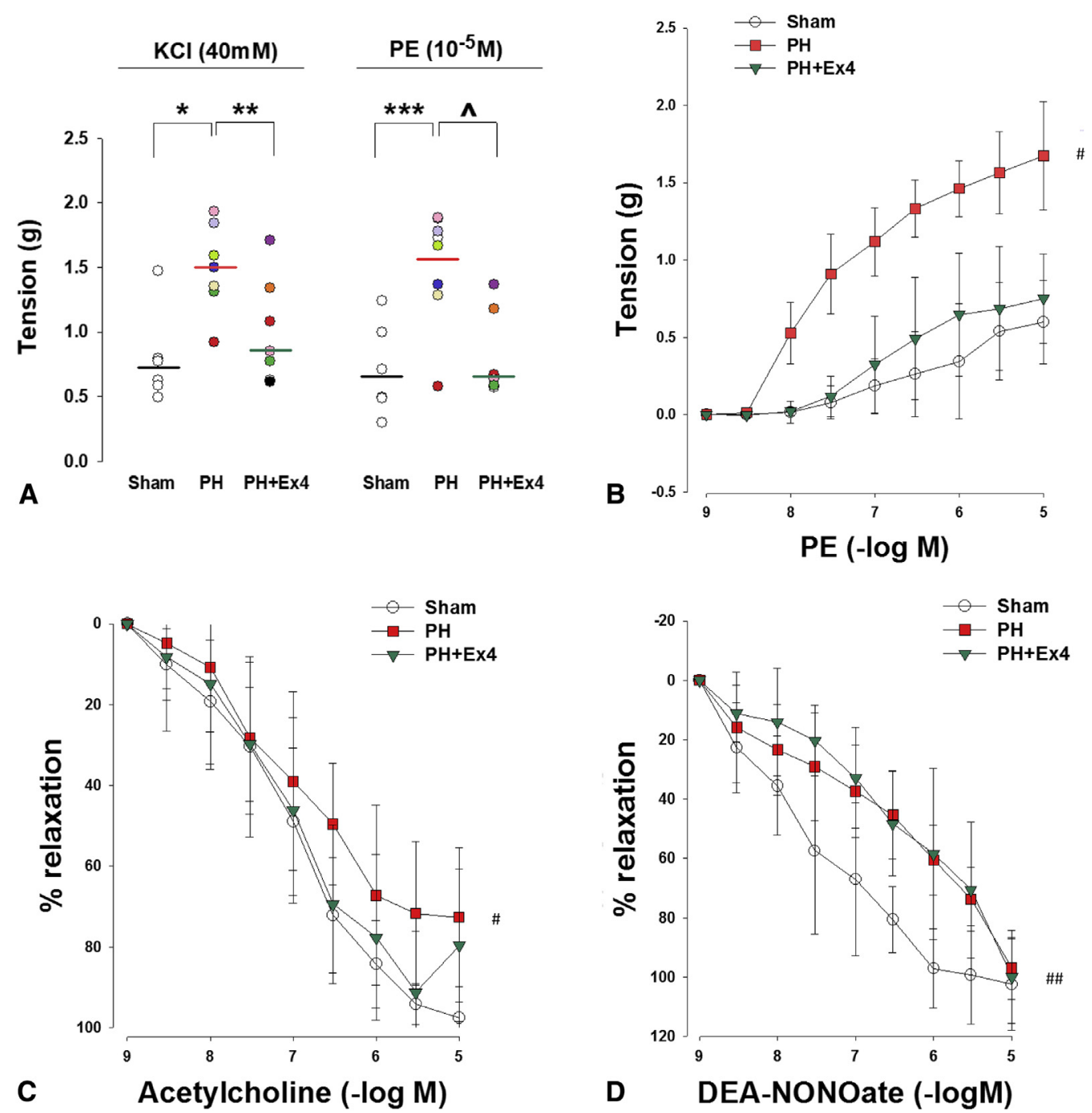

FIGURE 2. Vasomotor function analysis of pulmonary arteries (PAs) from rats with pulmonary hypertension $(P H)$ with or without exendin-4 (Ex4) treatment. A, Contractile responses to $40 \mathrm{mM}$ potassium chloride $(\mathrm{KCl})$ and phenylephrine $(\mathrm{PE})\left(10^{-5} \mathrm{M}\right)$. B, Contractile responses of the PA to cumulative addition of PE $\left(10^{-9}-10^{-5} \mathrm{M}\right)$. C, Relaxation responses to cumulative addition of acetylcholine. D, Relaxation responses to cumulative addition of diethylammonium (Z)-1-(N, N-diethylamino) diazen-1-ium-1, 2-diolate (DEA-NONOate)/nitric oxide. Relaxation was obtained during contraction using an effective concentration that achieved $60 \%$ maximum contraction of PE. Data were analyzed using analysis of variance and are presented as mean \pm standard deviation; $\mathrm{n}=6$ to 8 rats/group. $* P=.004$ for $\mathrm{PH}$ versus $\mathrm{PH}+\mathrm{Ex} 4$ and sham. $* * P=.017$ for $\mathrm{PH}$ versus $\mathrm{PH}+\mathrm{Ex} 4$ and sham. ***P $P$.001. ${ }^{\wedge} P<.001$ for PH versus $\mathrm{PH}+\mathrm{Ex} 4$ and sham. ${ }^{\#} P<.05$ for $\mathrm{PH}$ versus $\mathrm{PH}+\mathrm{Ex} 4$ and sham. ${ }^{\# \#} P<.05$ for $\mathrm{PH}$ versus $\mathrm{PH}+\mathrm{Ex} 4$ and sham.

proteins (Figure 4, $B$ and $C$ ). Tissue matrix metalloproteinase-2 levels were reduced in the $\mathrm{PH}+\mathrm{Ex} 4$ group (Figure 4, $D$ ).

\section{Ex4 Attenuated the Medial Thickness of PA and Intra-acinar Arterioles}

Medial thickness was significantly increased in the main PA and intra-acinar arterioles of rats with flowinduced PH (Figure E4, $A$ and Figure 5, respectively). Three weeks of Ex4 treatment reduced the medial thickness in both the main PA (Figure E4, A) and intra-acinar arterioles (Figure 5). Plexiform arteriopathy was identified around intra-acinar arterioles with or without Ex4 treatment (Figure 5, $A$ and $B$ ). IHC demonstrated increased IL-1 $\beta$ expression in the remodeled main $\mathrm{PA}$ of $\mathrm{PH}$ rats, and this effect was mitigated by Ex4 (Figure E4).

\section{DISCUSSION}

Although our previous study suggested that the creation of an aortocaval fistula induces medial hypertrophy and hypertension in the PA, the clinical severity, particularly the survival of the animals, was not remarkable. ${ }^{22}$ van Albada and colleagues ${ }^{13}$ developed a more clinically relevant model of $\mathrm{PH}$ by injecting a single dose of monocrotaline before creating a large systemic left-to- 


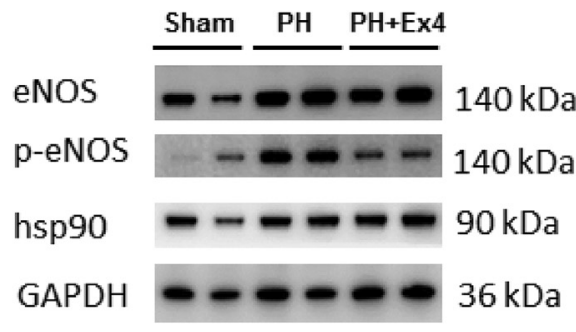

A

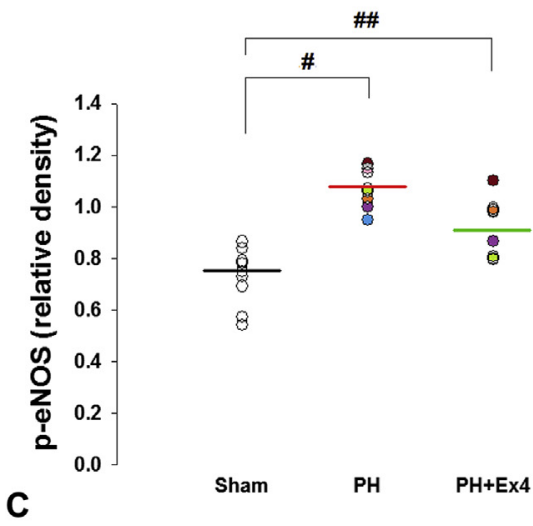

*

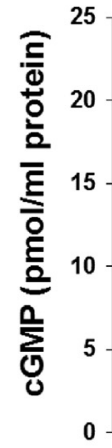

E

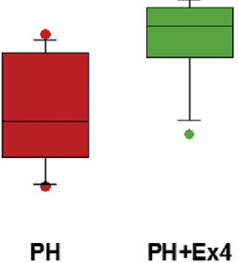

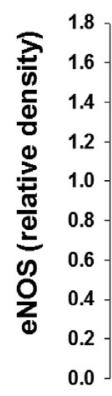

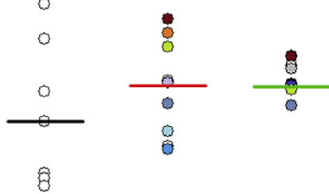

Sham

PH

PH+Ex4
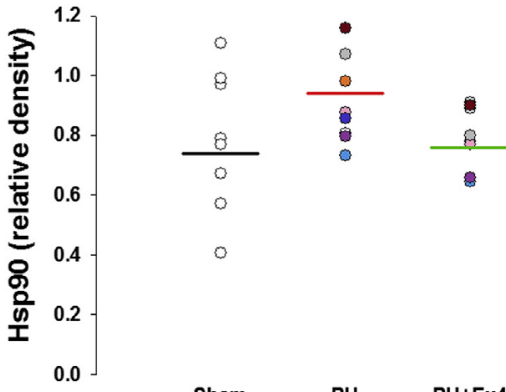

D

Sham

PH+Ex4
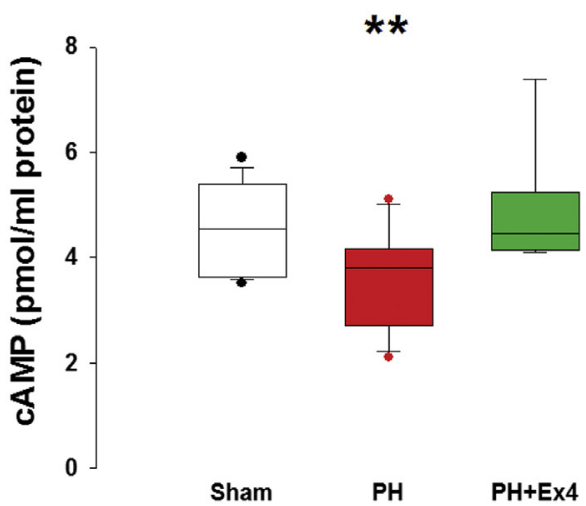

F

FIGURE 3. Immunoblotting and enzyme-linked immunosorbent assay of pulmonary artery tissue. A, Representative proteins associated with nitric oxide production. Quantification of western blotting for (B) Endothelial nitric oxide synthase (eNOS) $(P=.059)$. C, phosphorylated (p)-eNOS. D, Heat shock protein (hsp) $90(P=.543) ; \mathrm{n}=8$ to 10 /group. E and $\mathrm{F}$, Tissue concentrations of cyclic guanosine monophosphate $(c G M P)$ and cyclic adenosine monophosphate $(c A M P)$ in pulmonary artery homogenates after a 30-minute incubation with 3-isobutyl-1-methylxanthine $\left(10^{-3} \mathrm{M}\right){ }^{*} P<.05$. ${ }^{* *} P<.05$ for pulmonary hypertension $(P H)$ versus sham and $\mathrm{PH}+$ exendin-4 $(E x 4)$, respectively; $\mathrm{n}=8$ to $10 /$ group with 2 replicates. ${ }^{\#} P<.001 .{ }^{\# \#} P<.001$.

right shunt in rats. Monocrotaline, a toxic pyrrolizidine alkaloid extracted from the plant Crotalaria spectabilis, has been used since the 1960 s to induce $\mathrm{PH}$ in laboratories. ${ }^{25}$ Injection of monocrotaline induces a prominent inflammatory reaction, which is an important component of the pathogenesis of patients with PAH. ${ }^{26,27}$ The presence of the left-to-right shunt, pulmonary plexogenic arteriopathy, and the subsequent right heart remodeling in our model suggest the potential for clinical inferences to diseases with left-to-right shunt. $^{25,28}$ Our present findings confirm that this modification significantly enhances the mortality and cardiopulmonary dysfunction of rats. Simultaneous injection of monocrotaline and creation of aortocaval shunts remodeled the RV and PA, and mortality increased significantly 2 weeks after $\mathrm{PH}$ induction.

Increased pulmonary blood flow enhances eNOS and p-eNOS expression and reduces cGMP (nitric oxide second 


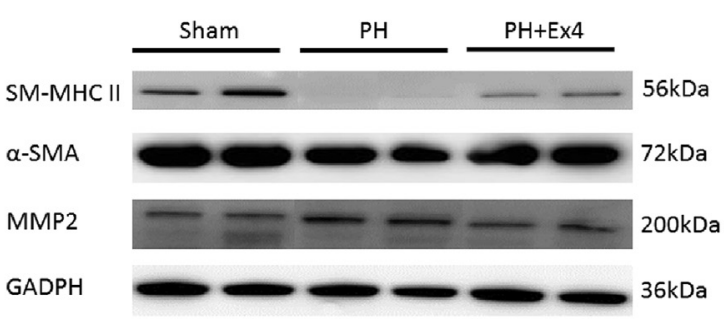

A

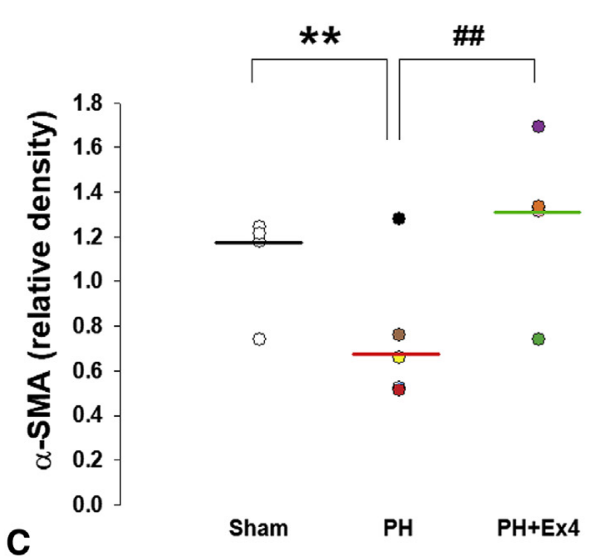

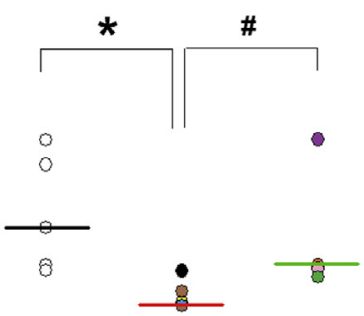

Sham $\quad \mathrm{PH} \quad \mathrm{PH}+\mathrm{Ex} 4$

B
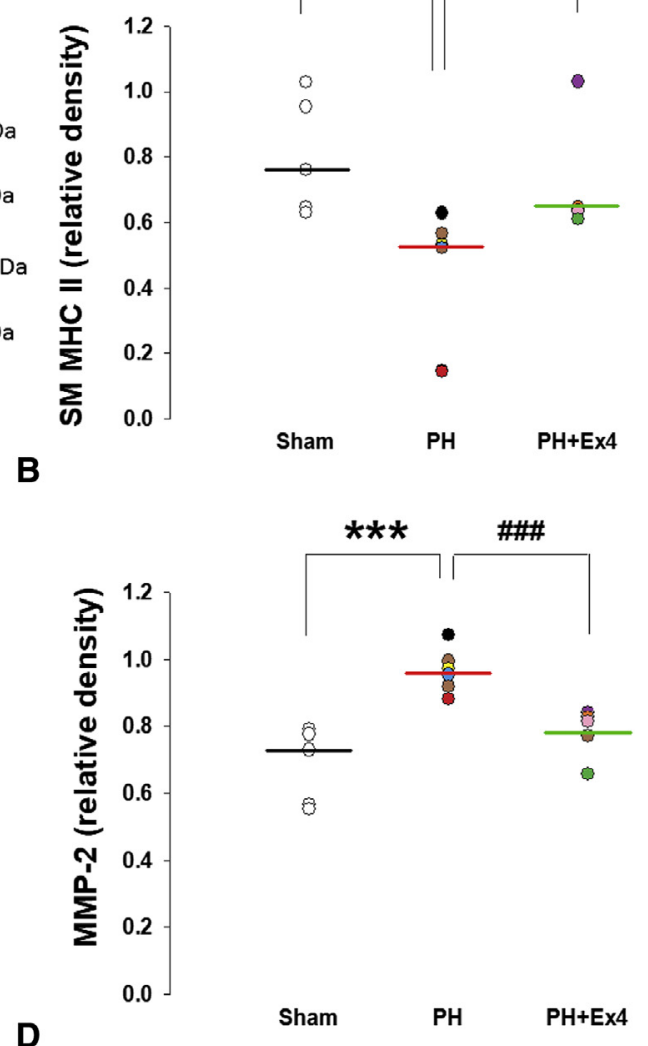

FIGURE 4. Exendin-4 (Ex4) attenuated de-differentiation of vascular smooth muscle cells in pulmonary arteries from rats with flow-induced pulmonary hypertension $(P H)$. A, Representative immunoblots of smooth muscle myosin heavy chain (SM-MHC) class II, $\alpha$-smooth muscle actin (SMA), and matrix metalloproteinase $(M M P)-2$. B-D, Quantitative analysis of protein levels. $\mathrm{n}=5$ to 6/group. ${ }^{*} P<.05 . * * P=.004 .{ }^{* * *} P=.001 .{ }^{\#} P<.05 .{ }^{\# \#} P=.004$.

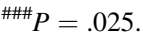

messenger) levels in the PA. ${ }^{22}$ Ex4 enhances eNOS and nitric oxide biosynthesis in cultured endothelial cells by activating Glp-1 receptor-dependent protein kinase A-phosphoinositide-3 kinase (PKA-PI3K)/Akt-eNOS pathways. ${ }^{29}$ However, excessive nitric oxide may trigger nitric oxide-cGMPindependent pathways to increase oxidative stress. ${ }^{30}$ The impaired endothelial-independent relaxation responses in the PA from Ex4-treated rats indicate the presence of adverse effects of nitric oxide in our model. In our study, eNOS/p-eNOS protein levels were unaffected by Ex4, whereas the coupling activity of eNOS was improved, as supported by the restoration of cGMP tissue levels. Consequently, endothelial function and pulmonary hemodynamic measures were improved in the Ex4-treated rats.

IL- $1 \beta$ is associated with primary and secondary $\mathrm{PH}^{26,31}$ In our study, the serum and PA tissue contents of caspase- 1 and IL- $1 \beta$-associated signaling molecules were significantly increased in $\mathrm{PH}$ rats. Ex4 treatment significantly downregulated IL- $1 \beta$ levels in circulation and the pulmonary artery. IL- $1 \beta$ downregulates cAMP in PA VSMCs by downregulating adenylyl cyclase in the p38 mitogen-activated protein kinase-dependent pathway, ${ }^{32}$ which supports our finding of increased tissue cAMP levels in the PA of Ex4-treated PH rats. Accordingly, our study demonstrates that IL-1 $\beta$ may play an important role in flow-induced pulmonary arteriopathy, which was attenuated by systemic administration of Ex4.

Next, we examined the phenotypic modulation of PA VSMCs. In the de-differentiated state, VSMCs re-enter the cell cycle. ${ }^{33}$ The PA of flow-induced PH rats showed reduced expression of $\alpha$-SMA and SM-MHC-II, suggesting that VSMCs de-differentiated from the contractile to the synthetic phenotype in response to the increased blood flow in PH. ${ }^{34}$ De-differentiation of VSMCs is essential for vascular remodeling and enlargement of the internal diameter of blood vessels, which normalizes the increase in shear stress. ${ }^{14}$ In this study, Ex4 treatment clearly restored pulmonary VSMCs to the contractile phenotype with enhanced $\alpha$-SMA and SM-MHC-II expression. Moreover, the increased cGMP/cAMP concentration in Ex4-treated rats may contribute to the contractile phenotypic switch of VSMCs in the remodeled PA. ${ }^{35}$

Our study has several limitations. The PA remodeling observed in this model is recognized as clinically relevant, 


\section{Sham}

A
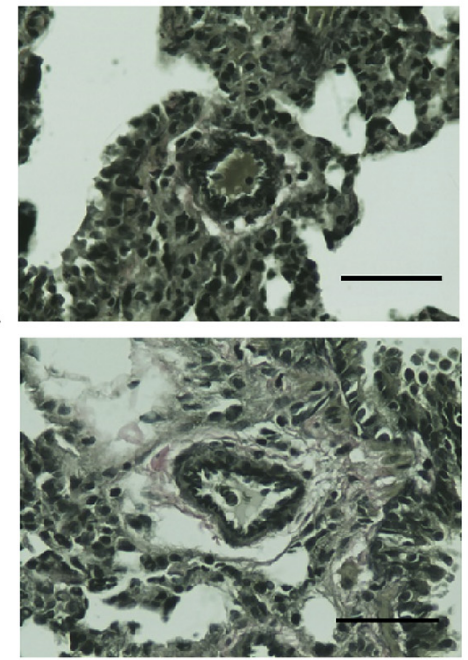

PH
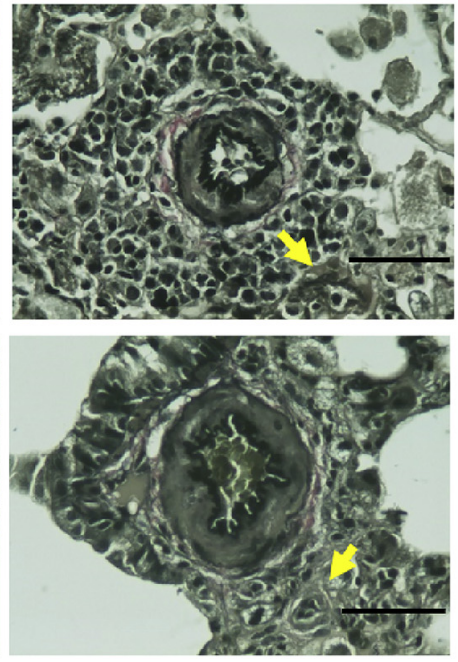

PH+Ex4
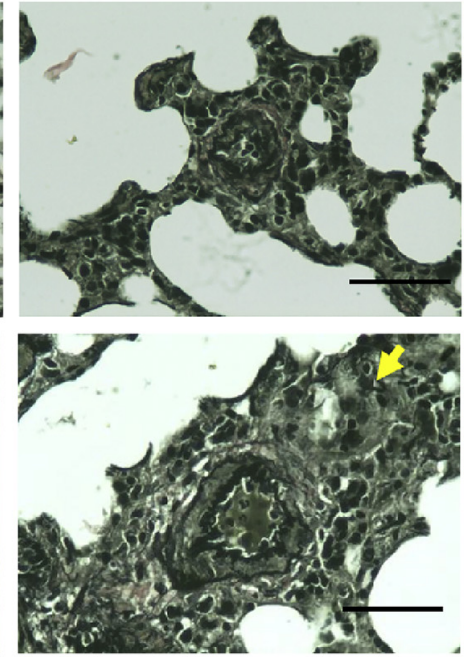

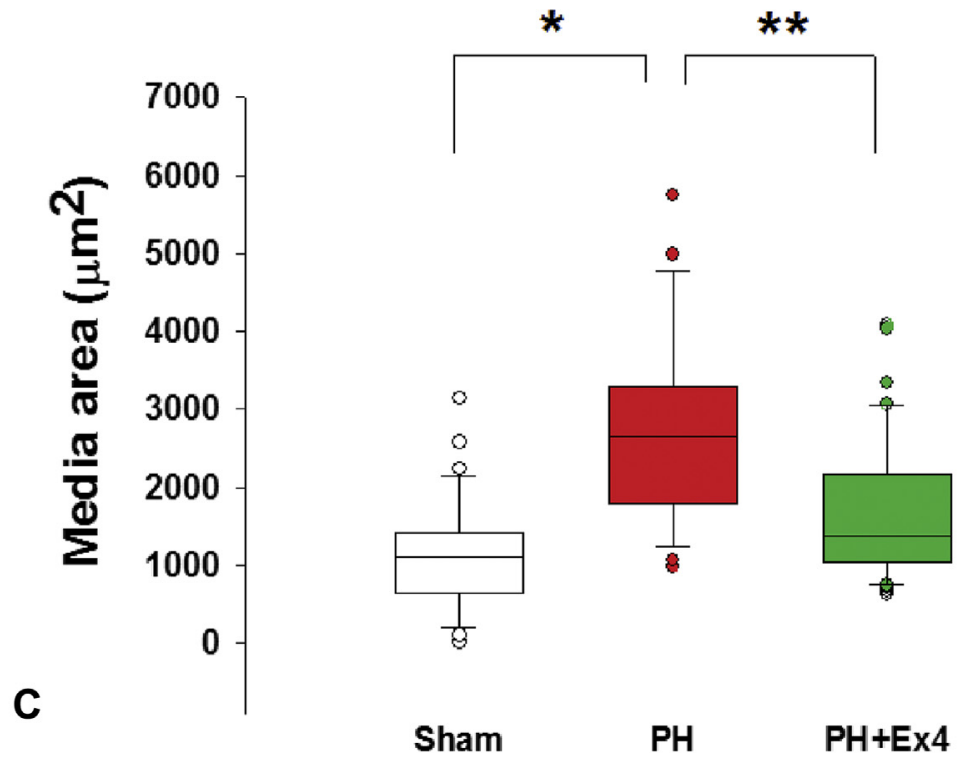

FIGURE 5. Exendin-4 (Ex4) attenuated medial hyperplasia of intra-acinar pulmonary vessels in rats with flow-induced pulmonary hypertension $(P H)$. Verhoeff staining of pulmonary arterioles with a diameter (A) $<50 \mu \mathrm{m}$ and (B) 50 to $100 \mu \mathrm{m}$. Plexiform angiopathy was identified around pathologic arterioles in PH-induced rats (yellow arrow). C, Quantitative analysis of intra-acinar arterioles $(<100 \mu \mathrm{m}) . \mathrm{n}=6 /$ group, $\times 400 \mathrm{magnification}$; scale bar, $50 \mu \mathrm{m} . * P<.05 . * * P<.05$.

but time-related pathophysiologic differences from human congenital heart diseases still exist (Video 1). ${ }^{13}$ Furthermore, our analyses did not account for the residual impaired endothelial-independent relaxation response in the vasomotor function test. Nevertheless, our findings support that the extraglycemic therapeutic effects of Glp-1 analogs are potentially useful in the cardiovascular system. ${ }^{9}$

\section{CONCLUSIONS}

Our study clearly demonstrated that monocrotaline administration followed by systemic left-to-right shunt creation induced consistent $\mathrm{PH}$ and pulmonary arteriopathy, leading to progressive RV maladaptive remodeling and increased mortality after 6 weeks. Ex4 treatment improved vasoreactivity in the PA via direct vasoactive, anti-inflammatory, and VSMC phenotypic modulatory effects. Furthermore, the improvement of pulmonary arteriopathy potentiated RV performance and reduced overall mortality. Therefore, our study highlights the beneficial extraglycemic effect of Ex4 as a potential therapeutic agent for regression of pulmonary arteriopathy secondary to flow-induced $\mathrm{PH}$. 


\section{Conflict of Interest Statement}

Authors have nothing to disclose with regard to commercial support.

\section{References}

1. Delcroix M, Howard L. Pulmonary arterial hypertension: the burden of disease and impact on quality of life. Eur Respir Rev. 2015;24:621-9.

2. Simonneau G, Gatzoulis MA, Adatia I, Celermajer D, Denton C, Ghofrani A, et al. Updated clinical classification of pulmonary hypertension. J Am Coll Cardiol. 2013;62:D34-41.

3. Engelfriet PM, Duffels MG, Moller T, Boersma E, Tijssen JG, Thaulow E, et al. Pulmonary arterial hypertension in adults born with a heart septal defect: the Euro Heart Survey on adult congenital heart disease. Heart. 2007;93: 682-7.

4. Lowe BS, Therrien J, Ionescu-Ittu R, Pilote L, Martucci G, Marelli AJ. Diagnosis of pulmonary hypertension in the congenital heart disease adult population impact on outcomes. J Am Coll Cardiol. 2011;58:538-46.

5. Ramjug S, Hussain N, Hurdman J, Billings C, Charalampopoulos A, Elliot CA, et al. Pulmonary arterial hypertension associated with congenital heart disease: comparison of clinical and anatomic-pathophysiologic classification. J Heart Lung Transplant. 2016;35:610-8.

6. Kanwar MK, Thenappan T, Vachiery JL. Update in treatment options in pulmonary hypertension. J Heart Lung Transplant. 2016;35:695-703.

7. Brunton S, Davidson JA. Exenatide once weekly: a review of pharmacology and treatment considerations in type 2 diabetes. Clin Ther. 2016;38:582-94.

8. Ban K, Noyan-Ashraf MH, Hoefer J, Bolz S-S, Drucker DJ, Husain M. Cardioprotective and vasodilatory actions of glucagon-like peptide 1 receptor are mediated through both glucagon-like peptide 1 receptor-dependent and-independent pathways. Circulation. 2008;117:2340-50.

9. Anagnostis P, Athyros VG, Adamidou F, Panagiotou A, Kita M, Karagiannis A, et al. Glucagon-like peptide-1-based therapies and cardiovascular disease: looking beyond glycaemic control. Diabetes Obes Metab. 2011;13:302-12.

10. Hirata Y, Kurobe H, Nishio C, Tanaka K, Fukuda D, Uematsu E, et al. Exendin-4, a glucagon-like peptide-1 receptor agonist, attenuates neointimal hyperplasia after vascular injury. Eur J Pharmacol. 2013;699:106-11.

11. Arakawa M, Mita T, Azuma K, Ebato C, Goto H, Nomiyama T, et al. Inhibition of monocyte adhesion to endothelial cells and attenuation of atherosclerotic lesion by a glucagon-like peptide-1 receptor agonist, exendin-4. Diabetes. 2010;59: 1030-7.

12. Zhao L, Li AQ, Zhou TF, Zhang MQ, Qin XM. Exendin-4 alleviates angiotensin II-induced senescence in vascular smooth muscle cells by inhibiting Rac1 activation via a cAMP/PKA-dependent pathway. Am J Physiol Cell Physiol. 2014:307:C1130-41.

13. van Albada ME, Schoemaker RG, Kemna MS, Cromme-Dijkhuis AH, van Veghel R, Berger RMF. The role of increased pulmonary blood flow in pulmonary arterial hypertension. Eur Respir J. 2005;26:487-93.

14. Roan JN, Tsai YC, Chen IW, Chang SW, Huang CC, Lam CF. Inhibition of cyclooxygenase-2 modulates phenotypic switching of vascular smooth muscle cells during increased aortic blood flow. Heart Vessels. 2012;27:307-15.

15. Roan JN, Fang SY, Chang SW, Hsu CH, Huang CC, Chiou MH, et al. Rosuvastatin improves vascular function of arteriovenous fistula in a diabetic rat model. J Vasc Surg. 2012;56:1381-9.e1.

16. Shirazi RH, Dickson SL, Skibicka KP. Gut peptide GLP-1 and its analogue, Exendin-4, decrease alcohol intake and reward. PLoS One. 2013;8:e61965.

17. Hsu CY, Fang SY, Chen YZ, Roan JN, Chang SW, Huang CC, et al. Cardiovascular protection of activating KATP channel during ischemiareperfusion acidosis. Shock. 2012;37:653-8.

18. Lee JS, Fang SY, Roan JN, Jou IM, Lam CF. Spinal cord injury enhances arterial expression and reactivity of alpha1-adrenergic receptors-mechanistic investigation into autonomic dysreflexia. Spine J. 2016;16:65-71.
19. Koyama M, Furuhashi M, Ishimura S, Mita T, Fuseya T, Okazaki Y, et al Reduction of endoplasmic reticulum stress by 4-phenylbutyric acid prevents the development of hypoxia-induced pulmonary arterial hypertension. Am J Physiol Heart Circ Physiol. 2014;306:H1314-23.

20. Lam CF, Roan JN, Lee CH, Chang PJ, Huang CC, Liu YC, et al. Transplantation of endothelial progenitor cells improves pulmonary endothelial function and gas exchange in rabbits with endotoxin-induced acute lung injury. Anesth Analg. 2011;112:620-7.

21. Fang SY, Roan JN, Lin Y, Hsu CH, Chang SW, Huang CC, et al Rosuvastatin suppresses the oxidative response in the venous limb of an arteriovenous fistula and enhances the fistula blood flow in diabetic rats. J Vasc Res. 2014;51:81-9.

22. Lam CF, Peterson TE, Croatt AJ, Nath KA, Katusic ZS. Functional adaptation and remodeling of pulmonary artery in flow-induced pulmonary hypertension. Am J Physiol Heart Circ Physiol. 2005;289:H2334-41.

23. Dahal BK, Kosanovic D, Kaulen C, Cornitescu T, Savai R, Hoffmann J, et al Involvement of mast cells in monocrotaline-induced pulmonary hypertension in rats. Respir Res. 2011;12:60.

24. Farrar DJ, Woodard JC, Chow E. Pacing-induced dilated cardiomyopathy increases left-to-right ventricular systolic interaction. Circulation. 1993;88: 720-5.

25. Stenmark KR, Meyrick B, Galie N, Mooi WJ, McMurtry IF. Animal models of pulmonary arterial hypertension: the hope for etiological discovery and pharmacological cure. Am J Physiol Lung Cell Mol Physiol. 2009;297:L1013-32.

26. Rabinovitch M, Guignabert C, Humbert M, Nicolls MR. Inflammation and immunity in the pathogenesis of pulmonary arterial hypertension. Circ Res. 2014;115:165-75.

27. Ferraris VA. Increased understanding leads to increased complexity: molecular mechanisms of pulmonary arterial hypertension. J Thorac Cardiovasc Surg. 2016;152:1188-90

28. Hoffman JI, Rudolph AM, Heymann MA. Pulmonary vascular disease with congenital heart lesions: pathologic features and causes. Circulation. 1981;64 873-7.

29. Erdogdu O, Nathanson D, Sjoholm A, Nystrom T, Zhang Q. Exendin-4 stimulates proliferation of human coronary artery endothelial cells through eNOS-, PKA- and PI3K/Akt-dependent pathways and requires GLP-1 receptor. Mol Cell Endocrinol. 2010;325:26-35.

30. Takaya T, Hirata K, Yamashita T, Shinohara M, Sasaki N, Inoue N, et al A specific role for eNOS-derived reactive oxygen species in atherosclerosis progression. Arterioscler Thromb Vasc Biol. 2007;27:1632-7.

31. Groth A, Vrugt B, Brock M, Speich R, Ulrich S, Huber LC. Inflammatory cytokines in pulmonary hypertension. Respir Res. 2014;15:47.

32. El-Haroun H, Clarke DL, Deacon K, Bradbury D, Clayton A, Sutcliffe A, et al IL-1beta, BK, and TGF-beta1 attenuate PGI2-mediated cAMP formation in human pulmonary artery smooth muscle cells by multiple mechanisms involving p38 MAP kinase and PKA. Am J Physiol Lung Cell Mol Physiol. 2008;294: L553-62.

33. Owens GK, Kumar MS, Wamhoff BR. Molecular regulation of vascular smooth muscle cell differentiation in development and disease. Physiol Rev. 2004;84: 767-801.

34. Riha GM, Lin PH, Lumsden AB, Yao Q, Chen C. Roles of hemodynamic forces in vascular cell differentiation. Ann Biomed Eng. 2005;33:772-9.

35. Yang HM, Kim BK, Kim JY, Kwon YW, Jin S, Lee JE, et al. PPARgamma modulates vascular smooth muscle cell phenotype via a protein kinase G-dependent pathway and reduces neointimal hyperplasia after vascular injury. Exp Mol Med. 2013;45:e65.

Key Words: pulmonary arteriopathy, glucagon-like peptide (Glp)-1 analogs, exendin-4, flow-induced pulmonary hypertension, interleukin- $1 \beta$ 


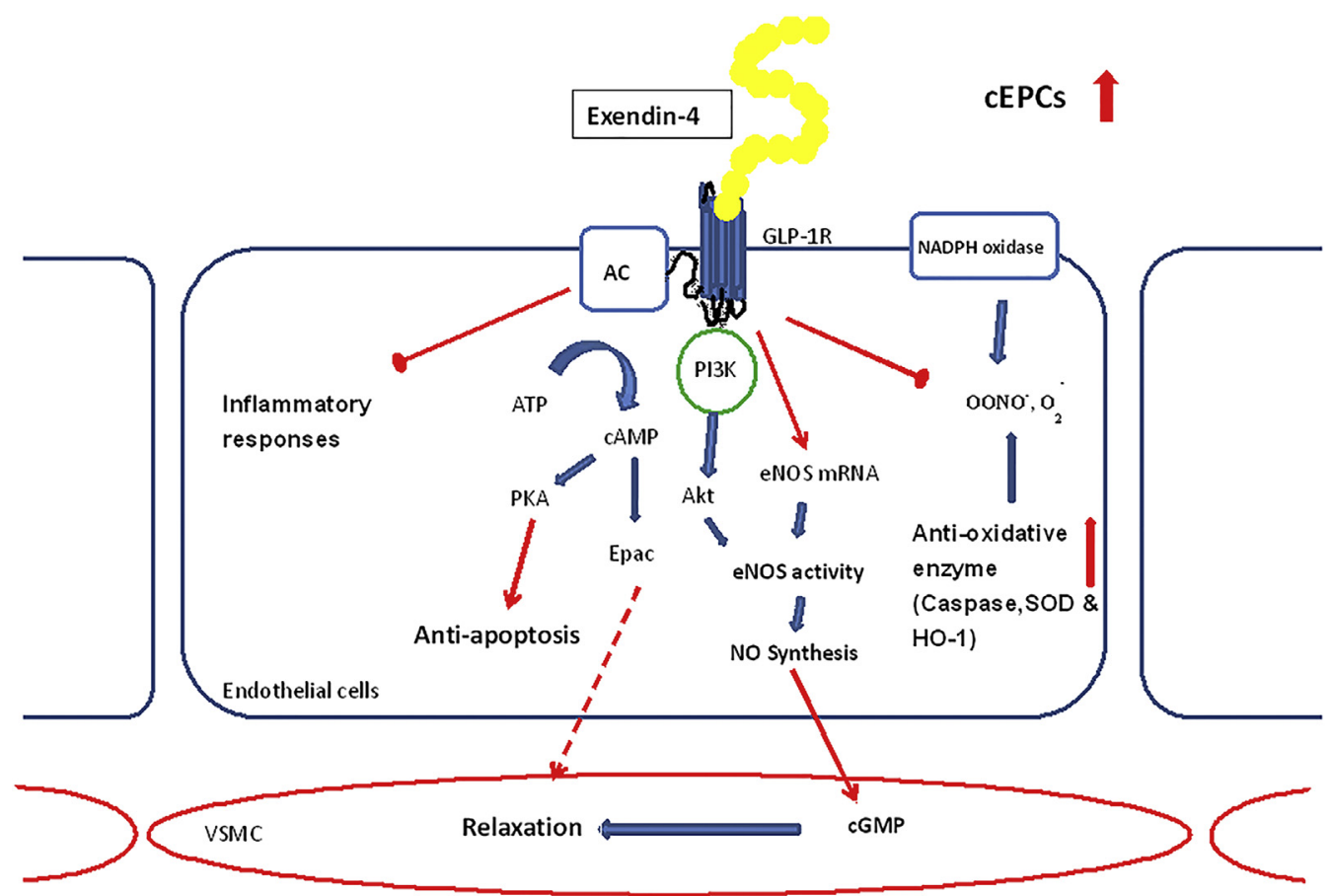

FIGURE E1. Summarized signal pathways of exendin-4 in endothelial and vascular smooth muscle cells. $A C$, Adenylate cyclase; $G L P-1 R$, glucagon like peptide-1 receptor; $N A D P H$, nicotinamide adenine dinucleotide phosphate hydrogen; $c E P C$, endothelial progenitor cell; $A T P$, adenosine triphosphate; $c A M P$, cyclic adenosine monophosphate; $P 13 K$, phosphoinositide-3 kinase; $P K A$, protein kinase A; eNOS, endothelial nitric oxide synthase; Epac, exchange protein directly activated by cAMP; $S O D$, superoxide dismutase; HO-1, heme-oxygenase-1; VSMC, vascular smooth muscle cell; $c G M P$, cyclic guanosine monophosphate.

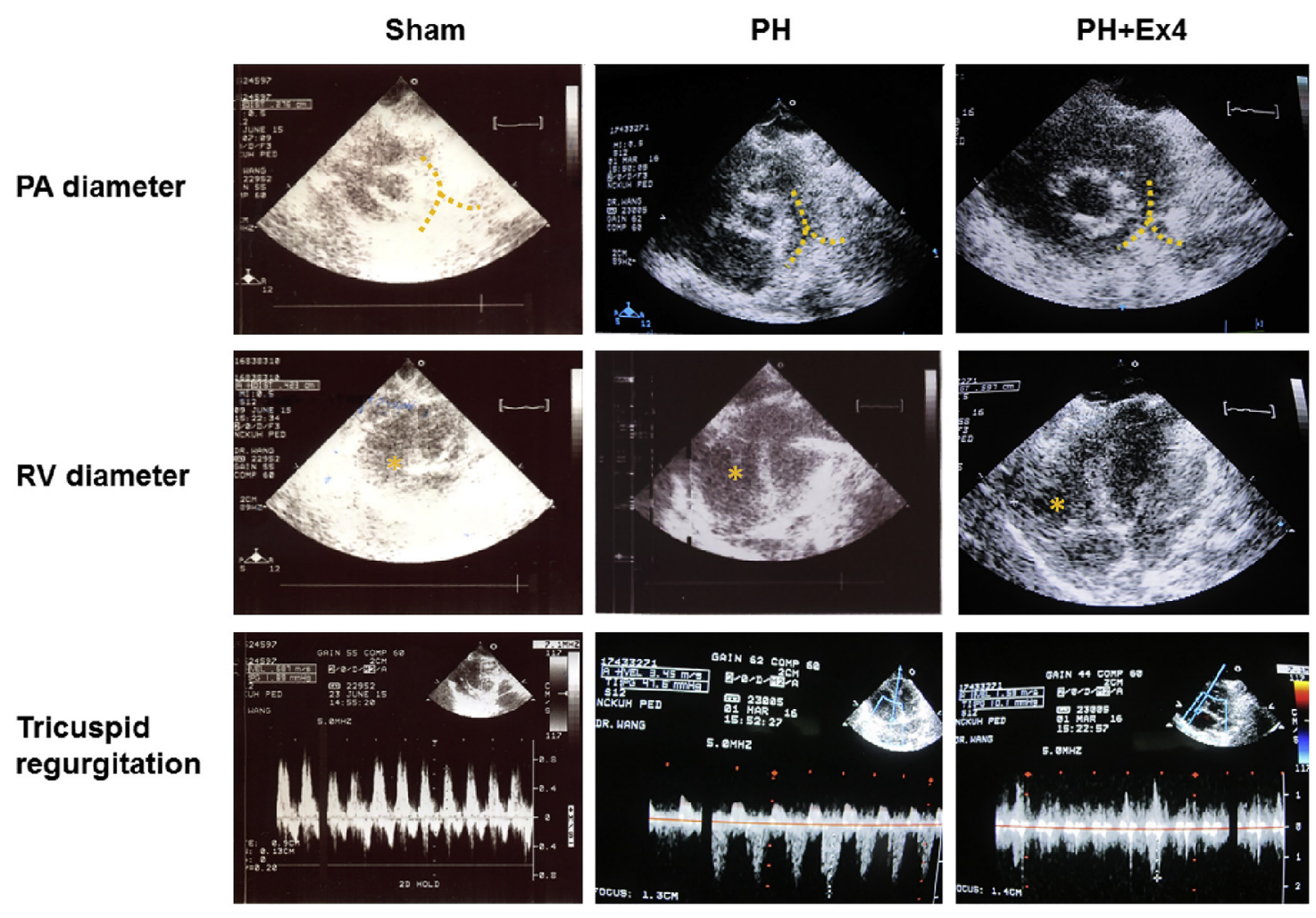

FIGURE E2. Representative echocardiographic images. Yellow dotted line indicates the position of main pulmonary artery $(P A)$ trunk. Yellow star indicates the position of right ventricle $(R V)$. $P H$, Pulmonary hypertension; Ex4, exendin-4. 


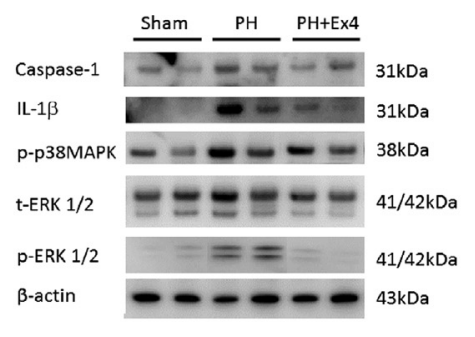

A

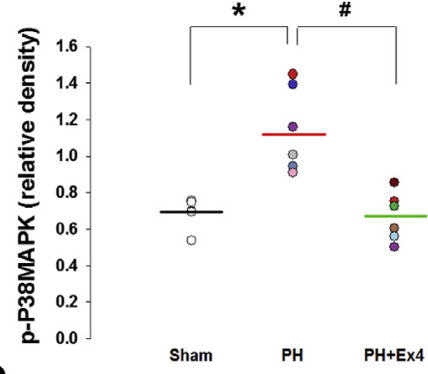

D

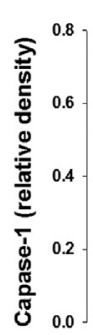

B

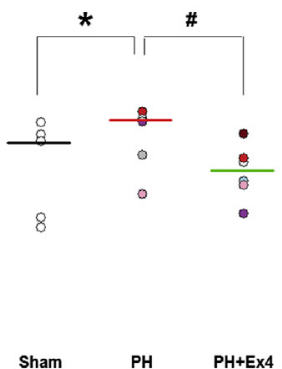

Sham

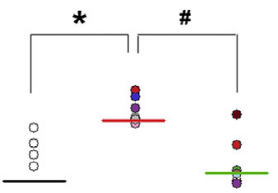

$\theta$

Sham

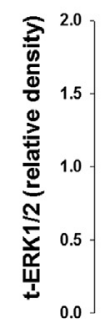

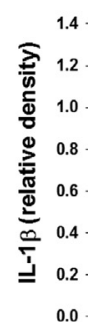

C
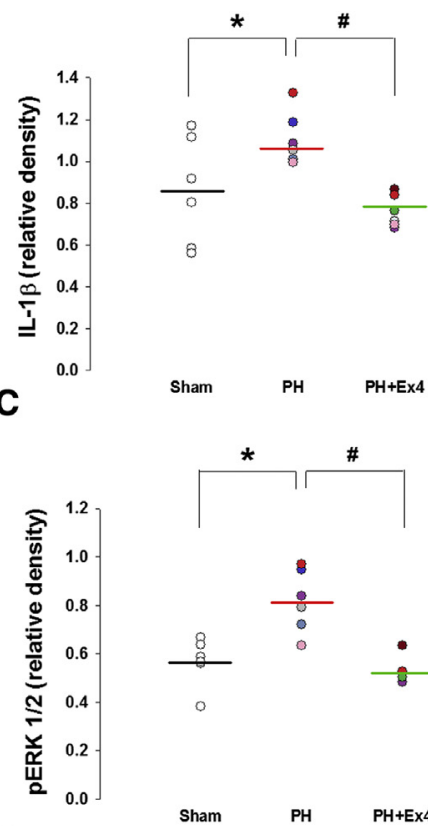

$\mathbf{E}$

FIGURE E3. Exendin-4 (Ex4) down-regulated interleukin (IL)-1 $\beta$ signaling-related proteins in pulmonary arteries (PAs). A, Representative immunoblots of caspase-1, IL-1 $\beta$, and associated signaling proteins in PAs from rats with pulmonary hypertension $(P H)$ treated with or without Ex4. B-F, Quantitative data for caspase-1, IL-1 $\beta$, phosphorylated (p)-p38 mitogen-activated protein kinase $(M A P K)$, total ( $\mathrm{t}$ )-extracellular-regulated signal kinase $(E R K) 1 / 2$, and p-ERK1/2. $\mathrm{n}=6$ /group. $* P<.05 . * * P<.05$. 


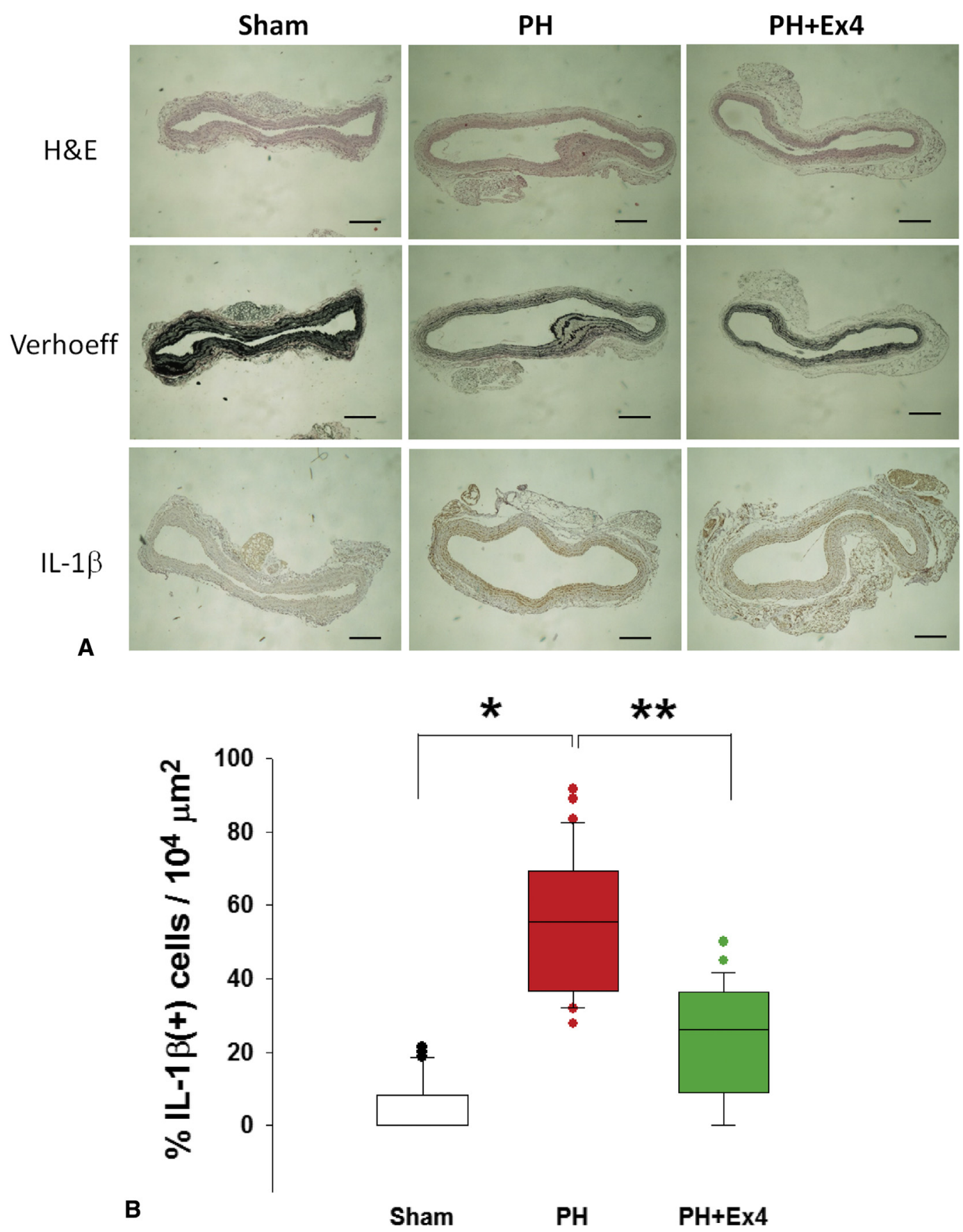

FIGURE E4. Histology of main pulmonary arteries (PAs) in flow-induced pulmonary hypertension $(P H)$. A, Hematoxylin and eosin, Verhoeff, and immunohistochemical staining of interleukin $(I L)-1 \beta$. B, Quantitative analysis of IL- $1 \beta$ expression in PAs. $\mathrm{n}=4$ animals per group. $\times 40$ magnification; scale bar, $50 \mu \mathrm{m}$. Ex4, Exendin-4. ${ }^{*} P<.05 .{ }^{\#} P<.05$. 
TABLE E1. Serum glucose and lipid profile of rats with flow-induced pulmonary hypertension (PH)

\begin{tabular}{lcccc}
\hline \multicolumn{1}{c}{ Variables } & Sham & PH & PH + Ex4 & P value \\
\hline Body weight & $295.1 \pm 110.8$ & $354.5 \pm 39.5$ & $336.7 \pm 34.5$ & .689 \\
Glucose AC (dL/mL) & $170.7 \pm 10.5$ & $148.5 \pm 6.0$ & $152.7 \pm 32.7$ & .070 \\
Triglyceride (mg/dL) & $48.5 \pm 26.3$ & $55.2 \pm 13.4$ & $80.9 \pm 27.6$ & .056 \\
Total cholesterol (mg/dL) & $49.8 \pm 3.9$ & $46.7 \pm 6.1$ & $45.4 \pm 12.9$ & $0.35 \pm 0.07$ \\
Creatinine (mg/dL) & $0.31 \pm 0.05$ & $0.33 \pm 0.02$ & .668 \\
\hline
\end{tabular}

Values are presented as mean \pm standard deviation. $\mathrm{n}=6$ to 8/group. PH, Pulmonary hypertension; Ex4, exendin-4; Glucose AC, before meal.

TABLE E2. Invasively measured hemodynamic data

\begin{tabular}{|c|c|c|c|c|}
\hline Variables & Sham & PH & PH + Ex4 & $P$ value \\
\hline Heart rate (beats/min) & $258.31 \pm 15.77$ & $296.31 \pm 1.19$ & $249.39 \pm 26.02$ & .885 \\
\hline $\mathrm{RVSP}_{\text {peak }}(\mathrm{mm} \mathrm{Hg})$ & $21.48 \pm 3.31$ & $67.14 \pm 5.75^{*}$ & $47.44 \pm 1.89 \dagger$ & $<.001$ \\
\hline RV-EDP (mm Hg) & $7.74 \pm 1.65$ & $10.72 \pm 1.91$ & $17.30 \pm 4.70$ & .207 \\
\hline $\operatorname{LVSP}_{\text {peak }}(\mathrm{mm} \mathrm{Hg})$ & $74.78 \pm 3.53$ & $82.62 \pm 1.03$ & $98.19 \pm 3.63 \ddagger$ & .001 \\
\hline LV-EDP (mm Hg) & $5.82 \pm 0.84$ & $6.32 \pm 0.92$ & $11.18 \pm 1.24 \S$ & .003 \\
\hline $\mathrm{RVSP}_{\text {peak }} / \operatorname{LVSP}_{\text {peak }}(\%)$ & $31.00 \pm 3.00$ & $79.29 \pm 3.58^{*}$ & $51.43 \pm 3.06 \dagger$ & $<.001$ \\
\hline
\end{tabular}

Values are presented as mean \pm standard error of the mean $\left(\mathrm{n}=6\right.$ /group). $P H$, Pulmonary hypertension; $E x 4$, exendin-4; $R V S P_{\text {peak }}$, right ventricle peak systolic pressure; $R V$-EDP, right ventricle end-diastolic pressure; $L V S P_{\text {peak }}$, left ventricle peak systolic pressure; $L V$ - $E D P$, left ventricle end-diastolic pressure. $* P<.05$ versus other groups using post hoc Tukey test. $\dagger P<.05$ versus other groups using post hoc Tukey test. $\ddagger P<.05$ versus PH using post hoc Dunn's method. $\S P<.05$ versus PH using post hoc Tukey test. 